研究論文：論文

\title{
幾何学的図形の面積知覚に及ぼす形と視角の効果
}

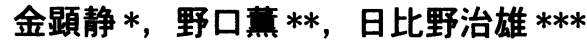 \\ *千葉大学大学院自然科学研究科, ** 日本大学文理学部, ***千葉大学工学部
}

\section{EFFECTS OF SHAPE AND VISUAL ANGLE ON AREA PERCEPTION OF GEOMETRICAL FIGURES}

\author{
Hyeon Jeong KIM*, Kaoru NOGUCHI**, Haruo HIBINO*** \\ *, ***Chiba University, 1-33 Yayoi-cho, Inage-ku, Chiba-shi 263-8522, JAPAN \\ **Nihon University, 3-25-40 Sakurajosui, Setagaya-ku, Tokyo 156-8550, JAPAN
}

\begin{abstract}
As seen in Mach's square and diamond , simple geometrial figures of equal area and different shapes look different in area or size. We found that triangular or diamond contours appear larger than circular or rectangular contours. In order to confirm this figural shape effect with varying visual angle of the stimuli, we adopted the method of area matching. The results supported the previous finding and showed that figural shape visual angle interaction had significant effects. That is, the figural shape effect was influened by changing the visual angle. These findings suggest the importance of figural extent or perimeter as a determinant of area perception.

Keywords : Area perception, Size perception, Figural extent, Shape effect, Visual angle
\end{abstract}

\section{1.はじめに}

我々の視覚環境には、いろいろな特徵をもつ多くの形が存 在しており、誰でも一度は、形の属性からなる知覚的な影響 を無意識的に経験したことがあるだろう。そして、これらの 視覚対象のさまざまな形態的特性は、われわれの感性に多く の影響を及ぼしていると考えられる。アルハイム (Arnheim) は、「芸術と視覚、Art and Visual Perception」という著書 で、形態のバランス（またはアンバランス）が人間の快と不 快感に染く関係しており、そのようなことからわれわれは常 にバランスのある構図を求めている [注 1] と記述している。 たとえば、レイアウトがよくないポスターや形と文字の大き さが非常に小さくて（または大きくて）、形がうまく把握でき なかった場合感じる一種の不快感は、形態のアンバランスか らなるものであろう。このように、見え易いあるいは見分け 易いといった視覚的経験は、どれもわれわれの感性に重要な 意味をもつといえる。さらに、最近はビジュアルストレス (Visual Stress)、すなわち視覚情報からなるストレスに関す る研究も進んでおり、ここでは視覚対象の特徵および状態が 感性と直接的な関係をもつことを示唆する。

そこ.で、形の属性からなる知覚特性、すなわち視知覚的側 面からの研究は、感性の体系化、工学化に重要な意味をもつ と考えられる。そして、視対象の時空間的特徵、すなわち大 きさ、色、配置、動きなどのような物理的特徴から生じる知 覚の現象的特徵または属性の体系的研究は、感性上学の基礎 となる。本研究は、形の属性からなる知覚的属性を、客観的 な情報と知覚的情報とのズレを感じる錯視に注目したものの、 対象の物理的大きさと知覚的大きさのズレについて調べるこ とを目的としている。心理学の多くの研究は、形の属性が知 覚に及ぼす影響を紹介しており、大きさの錯視は図形の幾何
学的属性により、対象の客観的な大きさと知覚的大きさとの ズレが生じるものと紹介している。一方、最近は大きさ知覚 を形の知覚との関連で研究することが多く、心理物理学的手 法での知覚的大きさの測定が試みられている。形の属性から なるさまざまな知覚属性を研究対象としたものの、図と地 (figure and ground, [注2]）または形の錯視（optical illusion [注 3]）がある。このように、心理学における形の知覚 研究は、形に対する人々の感覚を測るのに適すると考えられ る。大きさとは、通常物の形に随伴して知覚されるものであ るが、われわれは輪郭によって閉じられた形に対してだけで はなく、隙間のある円弧や散らばったドットなど、およそ視 空間に动がりをもって存在する視対象に対しても、大きさを 知覚する。そして、大きさという用語が面積（あるいは容積） だけではなく、間隔・角度・曲率・密度あるいは奥行・隔た りなどを違和感なく表現しているのは、もともと広がりとそ の程度や範囲を意味する用語だからであろう。そこで、本研 究は、大きさ知覚における人間の感性をより体系化、定量化 することを目指して、客観的大きさと知覚的大きさとの関係 を形の属性から調べてゆくことを試みたものである。ただし、 本研究では、幅広い意味で取られている大きさの概念を、図 形の面積に限定し、幾何学的閉鎖図形の面積の大きさ知覚に ついて調べることにした。幾何学的図形による大きさ知覚に 関する研究では、客観的に同じ面積の図形であっても、それ が星形、棈円、台形、三角形、四角形、円形であるかによっ て見かけの大きさは異なるということが明らかになっている [注 4]。Mach [注 5] は、同一の幾何学的要素を含む図形で あっても、正方形か菱形（正方形を $45^{\circ}$ 回転した図形）かと いう布置条件で見かけの大きさが著しく異なり、菱形配置の 方が大きく見えると報告している。さらに、線だけで描かれ 
表 1-1: 線図形における順位法による結果

\begin{tabular}{|c|c|c|c|c|c|c|c|c|c|c|}
\hline$r_{i}$ & $R_{i}$ & $\bigcirc$ & $\triangle$ & $\nabla$ & $\square$ & $\diamond$ & $\square$ & $\square$ & $\square$ & 0 \\
\hline 1 & 9 & & 6 & 3 & & & & & & \\
\hline 2 & 8 & & 3 & 6 & & & & & & \\
\hline 3 & 7 & 2 & & & 1 & 5 & & & & 1 \\
\hline 4 & 6 & 3 & & & 1 & 2 & & & & 3 \\
\hline 5 & 5 & 3 & & & 2 & & & & & 4 \\
\hline 6 & 4 & & & & 3 & 2 & 1 & 1 & 1 & 1 \\
\hline 7 & 3 & & & & 2 & & 4 & 2 & 1 & \\
\hline 8 & 2 & 1 & & & & & 3 & 4 & 1 & \\
\hline 9 & 1 & & & & & & 1 & 2 & 6 & \\
\hline & $\Sigma f_{i j} R_{i}$ & 49 & 78 & 75 & 41 & 55 & 23 & 20 & 15 & 49 \\
\hline & $M e$ & 5.7 & 8.8 & 8.3 & 4.3 & 6.6 & 2.6 & 2.1 & 1.3 & 5.4 \\
\hline & $\mathrm{RC}$ & 6 & 9 & 8 & 4 & 7 & 3 & 2 & 1 & 5 \\
\hline
\end{tabular}

表 1-2 : 面図形における順位法による結果

\begin{tabular}{|c|c|c|c|c|c|c|c|c|c|c|}
\hline$r_{i}$ & $\mathrm{R}_{\mathbf{i}}$ & & $\Delta$ & $\nabla$ & & & $\Delta$ & E & 0 & 0 \\
\hline 1 & 9 & & 5 & 4 & & & & & & \\
\hline 2 & 8 & & 4 & 5 & & & & & & \\
\hline 3 & 7 & 2 & 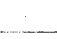 & & & 5 & & & & 2 \\
\hline 4 & 6 & 2 & & & & 3 & & & & 4 \\
\hline 5 & 5 & 4 & & & 3 & 1 & & & 1 & \\
\hline 6 & 4 & 1 & & & 4 & & 1 & 1 & & 2 \\
\hline 7 & 3 & & & & & & 3 & 5 & 1 & \\
\hline 8 & 2 & & & & 2 & & 3 & 3 & 1 & \\
\hline 9 & 1 & & & & & & 2 & & 6 & 1 \\
\hline & $\Sigma f_{i j} \mathrm{Ri}$ & 50 & 77 & 76 & 35 & 58 & 21 & 25 & 16 & 47 \\
\hline & Me & 5.4 & 8.6 & 8.4 & 4.1 & 6.6 & 2.3 & 2.8 & 1.3 & 5.9 \\
\hline$\ldots$ & Rc & 5 & 9 & 8 & 4 & 7 & 2 & 3 & 1 & 6 \\
\hline
\end{tabular}

た輪郭図形か、その内部を塗りつぶした充実図形か、また充 実図形でも白地に黒図形か逆に黒地に白図形であるかによっ てもその大きさは異なって知覚される。また、知覚された大 きさは、視空間における対象の拡がりの表現であるため、そ の規定要因として、当然、結像された視対象の網膜上での大 きさ、すなわち視角 [注 6] が重要である。視角以外のすべて の条件が同じであれば、実際知覚される大きさは視角にほぼ 正比例して変化する。視角と大きさ知覚に関する理論的立場 のなかでは、視角が見えの大きさに関わる知覚内容を直接的 に規定すると考える立場がある [注 7]。このように面積知覚 は、対象の見かけの形態や視角などさまざまな要因が関連し ている。しかし、これまでの面積知覚の研究ではこの二つの 項目、すなわち形と視角を同時に扱った研究はほとんどない。 一方、実際の日常現場では視覚対象は形態と視角の複数の情 報を持っており、それらの相互作用が知覚的大きさ、すなわ ち面積知覚に影響を及ぼす可能性もあると考えられる。そこ で、本研究は面積知覚に影響を及ぼす形態・視角の二つの要 因およびその相互関係について組織的な検討を試みた。

\section{2. 実験 I}

\section{1. 目的}

本実験は、Warren \& Pinneau [注 8]、Mach の形に関す る研究で用いられた幾何学的図形から「円形・止三角形・逆 正三角形・正方形・縦長四角形・横長四角形・五角形・六角 形・正菱形」の 9 種類の図形を選んで、形態的な違いが面積 知覚に与える影響を調べることを試みた。本研究では、これ までの大きさ知覚の研究ではあまり用いられていない順位法 (method of rank order) [注 9] を用い、大きさという特定 の様相が、形態的特徵によって影響を受けるかどうかを確か めることにした。そして、その結果から、順位尺度值を求め てどのような形態が知覚的大きさに大きく影響しているかを 検討した。また、実験に使う 9 種の図形を、線図形（線描さ れた輪郭図形）と面図形 (その内部を塗りつぶした充実図形) の二つの条件に分け、線または面の知覚からなる面積知覚へ の変化も検討することにした。

\section{2. 方法}

\subsection{1. 被験者}

止常視力 1.0 以上（矯正視力を含む）を有する 20 代の男女 大学生 9 名（男性 : 5 名、女性 : 4 名）が実験に参加する。

\subsection{2. 刺激}

円形・正三角形・逆正三角形・正方形・縦長四角形・横長 四角形・五角形・六角形・正菱形（正方形を $45^{\circ}$ 回転したも の）の9つの幾何学図形を刺激図形として使った。実験には、 面図形、線図形の 2 種類のテスト用紙を用意した。面図形が 描かれたテスト用紙は背景が白で、図形は灰色であった。線 図形が描かれたテスト用紙は、背景が白で、線の色は黒であっ た。2種類のテスト用紙とも描かれた図形の大きさは、それぞ れ $12 \mathrm{~cm}^{2}$ で同じ面積であった。そして、図形の配置位置は被 験者毎にランダムとした。

\subsection{3. 手続き}

各被験者に線図形と面図形の 2 種類のテスト用紙が与えら れ、それぞれに描かれた 9 つの図形の大きさを判断してもら た。判断時間の制限はなかった。判断の仕方としては、図形 が大きく見える方から小さく見える方に「1〜9」の順位を決 
表 1-3: 線図形の順位尺度

\begin{tabular}{|c|c|}
\hline Rc & Shape \\
\hline 9 & $\triangle$ \\
\hline 8 & $\nabla$ \\
\hline 7 & $\searrow$ \\
\hline 6 & $\bigcirc$ \\
\hline 5 & $\square$ \\
\hline 4 & $\square$ \\
\hline 3 & $\square$ \\
\hline 2 & $\square$ \\
\hline 1 & $\square$ \\
\hline
\end{tabular}

表 1-4: 面図形の順位尺度

\begin{tabular}{|c|c|}
\hline Rc & Shape \\
\hline 9 & $\Delta$ \\
\hline 8 & $\nabla$ \\
\hline 7 & \\
\hline 6 & \\
\hline 5 & \\
\hline 4 & \\
\hline 3 & \\
\hline 2 & \\
\hline 1 & \\
\hline
\end{tabular}

める方法を使い、得られた結果は、順位法による順位尺度値 を求めた。

\section{3. 結果および考察}

表 1-1 と表 1-2 は、それぞれ、線図形と面図形の知覚的大き さの順位を順位法により尺度化したものである。表 1-3 と表 1-4の列は刺激図形の種類を、行は大きさの順位 $r_{i}$ を上から 1、2、‥9 と示し、各々の表に示された数値は、各被験者か ら得られた各図形の順位を 9 名の被験䓃全体での頻度で表し たものである。表 1-3 と表 1-4は、順位の頻度から得られた 中央值 Meによる線図形と面図形の順位尺度值 $(\mathrm{Rc})$ を示す。 表 1-3 の線図形と表 1-4 の面図形の結果では、両方とも止三 角形、逆三角形、菱形の順に三つの図形が他の図形より大き く知覚されることを示した。しかし、それ以降の順位には、線 図形と面図形の違いが示された。

この結果は、正三角形、逆三角形、菱形の形態的特徽が、円 形、正方形、縦長正方形、横長止方形、五角形、六角形より 大きく知覚されることを示す。また、線図形か面図形かを問 わず、三角形と菱形の大きさの順位が大きいことは、今回の 実験において線と面による知覚的影響が少なかったことを示 す。しかし、大きさ知覚における形態的特徵による影響に関 しては、二うの三角形と菱形が止方形や円形より大きく知覚 された結果は、これまでの先行研究の結果で鋭角の図形が大 きさの過大視傾向をもつという結果と一致した。たとえば、表 1-3 と表 1-4の結果、Rcが高い正三角形、逆止三角形は、他 の刺激図形より鋭角の図形であり、菱形は図形の回転効果に より垂直方向の上下部の角度が実際より鋭角に知覚される [注 5] という。また、この結果は、Behraman \& Brown [注 10] が、大きさ知覚に影響する要因として指摘した「周の長 さ」、縦横比」、「内角」の三つの要因にも関係する。Behraman \&Brownが示すこれらの要因について、図形ごとに考察を求 めたのが図 1 と表 1-5 である。表 1-5 から、三角形が他の図 形と比較して一辺の長さが長く、周の長さも大きいことが分 かる。そして、菱形の縦横の幅が他の図形より大きいことが 確認できる。

以上の結果から、同じ面積で形態が異なる図形の大きさ判 断においては、Behraman \& Brownが報告した「維横比」に よる影響より、「縦横の幅」や「角度」が大きさ知覚に影響し、 「一辺の長さ」、横の幅」、鋭角」は過大視効果をもつことが 示唆された。また、止方形と菱形の現象的大きさの違いから

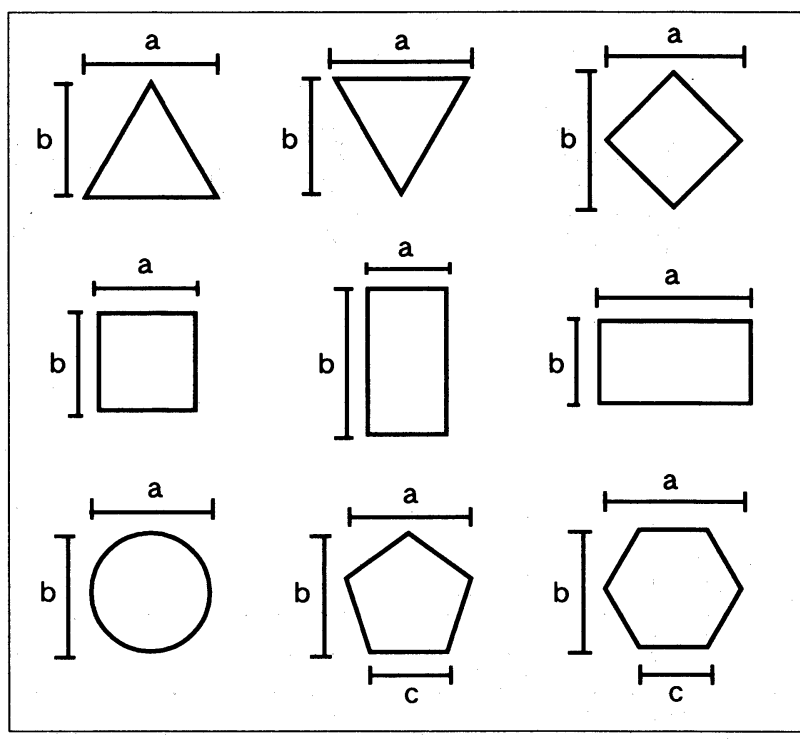

図 $1:$ 刺激図形の大きさ

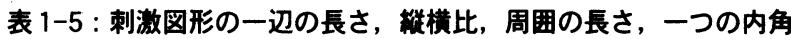

\begin{tabular}{|c|c|c|c|c|c|c|c|}
\hline & $\begin{array}{c}a \\
(\mathrm{c} \mathrm{m})\end{array}$ & $\begin{array}{c}\mathrm{b} \\
(\mathrm{cm})\end{array}$ & $\begin{array}{c}c \\
(\mathrm{~cm})\end{array}$ & $\begin{array}{c}\text { 栍桠の比 } \\
(\mathrm{b} / \mathrm{a})\end{array}$ & $(b / c)$ & $\begin{array}{c}\text { 周囲の長さ (L) } \\
(\mathrm{cm})\end{array}$ & 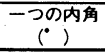 \\
\hline$\Delta$ & 5.26 & 4.56 & & 0.87 & & 15.78 & 60 \\
\hline$\nabla$ & 5.26 & 4.56 & & 0.87 & & 15.78 & 60 \\
\hline$\nabla$ & 4.90 & 4.90 & & 1.00 & & 13.84 & 90 \\
\hline$\square$ & 3.46 & 3.46 & & 1.00 & & 13.84 & 90 \\
\hline 綐長口 & 3.00 & 4.00 & & 1.33 & & 14.00 & 90 \\
\hline 椣長口 & 4.00 & 3.00 & & 0.75 & & 14.00 & 90 \\
\hline 0 & 3.90 & 3.90 & & 1.00 & & 12.27 & 360 \\
\hline 五角形 & 4.05 & 4.05 & 2.64 & 1.00 & 1.53 & 13.2 & 108 \\
\hline 六角形 & 4.30 & 3.72 & 2.15 & 0.87 & 1.73 & 12.9 & 120 \\
\hline
\end{tabular}

は、図形自体に変化がなく、網膜像の形の変化がなくても、 図形の回転又は方向によりその見えの大きさが異なることが 確認された。つまり、図形の回転は図形がもつ内的な、幾何 学的な構造を変えるものではなくても、見えの大きさ知覚に 大きく影響することが確かめられた。

しかしながら、実験 I の結果からは、客観的大きさと知覚 的大きさの差を定量化することが難しいため、次の実験から では、被験者調整法 [注 11] を用いて、客観的大きさと知覚 的大きさの差を調べることにした。刺激図形の種類を減らし、 図形の幾何学属性の縦横幅に注目しながら、異なった視角条 件での検討を試みた。そして、面積知覚における視角の効果 および形態と視角との相互関係を調べることにした。

\section{3. 実験 II}

\section{1. 目的}

視覚刺激の空間的特性においてとくに重要なものは、視対 象の大きさであり、最終的には網膜像の大きさである。しか し、網膜像の空間的特性を直接測定することは困難であるの で間接的に、しかも視対象の空間的特徴だけで評価できるこ とが望ましい。そこで、視対象が眼に対して張る角度、すな わち視角 (visual angle) によって網膜象の大きさを等価的に 表現することが多い。さらに、網膜像の大きさ、すなわち視 角は、大きさを規定するもっとも大きな要因といわれている。 一定の観察距離の場合、対象の客観的な大きさが大になるほ ど網膜像も大きくなり、同時にその見えの大きさも大きくな 


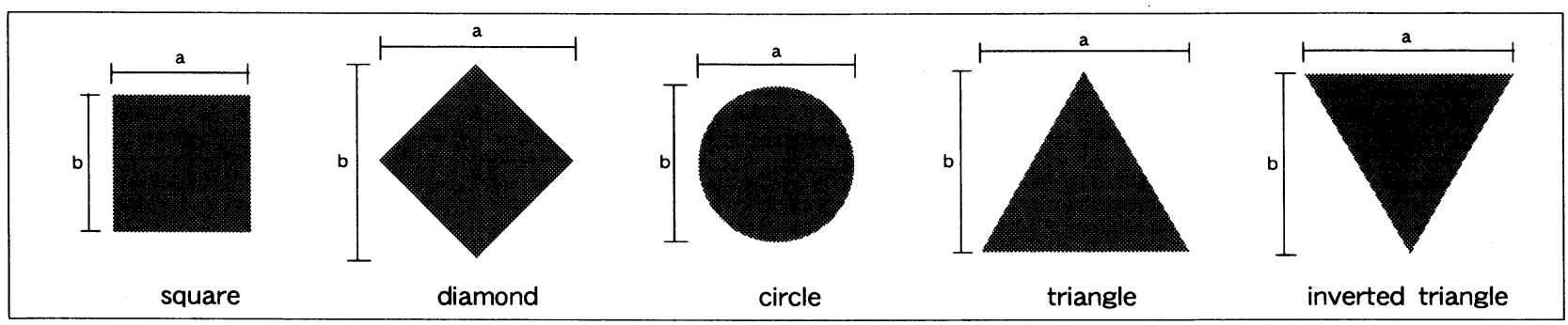

図 2-1: 刺激図形

表 2 : 刺激図形の面積と視角

\begin{tabular}{|c|c|c|c|c|c|c|c|c|c|c|c|}
\hline \multirow[b]{2}{*}{$\begin{array}{c}\text { area } \\
\left(\mathrm{cm}^{2}\right)\end{array}$} & \multirow[b]{2}{*}{ a side } & \multicolumn{2}{|c|}{ square } & \multicolumn{2}{|c|}{ diamond } & \multicolumn{2}{|l|}{ circle } & \multicolumn{2}{|c|}{ triangle } & \multicolumn{2}{|l|}{ inverted } \\
\hline & & $(\mathrm{cm})$ & $\begin{array}{c}\text { visua angle } \\
\left({ }^{\circ}\right)\end{array}$ & (cm) & $\begin{array}{c}\text { visua angle } \\
\left({ }^{\circ}\right)\end{array}$ & $(\mathrm{cm})$ & $\begin{array}{c}\text { visua angle } \\
\left({ }^{\circ}\right)\end{array}$ & $(\mathrm{cm})$ & $\begin{array}{c}\text { visua angle } \\
\text { ( ) }\end{array}$ & $\begin{array}{c}\text { triangle } \\
(\mathrm{cm})\end{array}$ & $\begin{array}{c}\text { visua angle } \\
\left({ }^{\circ}\right)\end{array}$ \\
\hline \multirow[t]{2}{*}{ small } & a & 4.90 & 4.68 & 6.95 & 6.64 & 5.53 & 5.28 & 7.44 & 7.11 & 7.44 & 7.11 \\
\hline & $b$ & 4.90 & 4.68 & 6.95 & 6.64 & 5.53 & 5.28 & 6.45 & 6.16 & 6.45 & 6.16 \\
\hline \multirow[t]{2}{*}{ medium } & $a$ & 6.93 & 6.62 & .9 .8 & 9.36 & 7.82 & 7.47 & 10.53 & 10.06 & 10.53 & 10.06 \\
\hline & $b$ & 6.93 & 6.62 & 9.8 & 9.36 & 7.82 & 7.47 & 9.12 & 8.71 & 9.12 & 8.71 \\
\hline \multirow[t]{2}{*}{ large } & $a$ & 9.80 & 9.36 & 13.86 & 13.24 & 11.06 & 10.56 & 14.89 & 14.22 & 14.89 & 14.22 \\
\hline & b & 9.80 & 9.36 & 13.86 & 13.24 & 11.06 & 10.56 & 12.9 & 12.32 & 12.9 & 12.32 \\
\hline
\end{tabular}

ることはきわめて明白な事実である。

Teightsoonian [注 12］は、一定の観察距離に提示された 線分、多角形の見えの大きさとその対象の面積の関係を調べ が、その結果、見えの大きさは、面積のべキ関数として表現 することができ、線分に対するべキ指数は $1.0 、$ 多角形と立体 に対するべキ指数はそれぞれ0.8、0.7であると報告した。ま た、Dumais \& Bradley [注 13] のは、図形の大きさ（主観 的輪郭図形により）を調べた結果、主観的輪郭の強さが照度 および視角の対数に比例して減少することを明らかにした。

この結果は、主観的輪郭の知覚に限られた結果ではあるが、 形の大きさ知覚に網膜的大きさ、すなわち視角が影響してい ることを示唆した。

そこで、本実験は、実験 I から得られた結果をもとに、刺 激図形の数を減らし、それらの図形の観察距離一定保ったま ま刺激図形の大きさ（視角）を 3 段階に変化する条件を設け て、形態的特徴が大きさ知覚に及ぼす効果の検討を試みた。

\section{2. 方法}

\subsection{1. 被験者}

止常視ノ 1.0 以上（矯止視」を含む）を有する 20 代男女大 学生 15 名（男性: 8 名、女性 7 名)。

\subsection{2. 装置・実験環境}

実験の制御にはパーソナルコンピュータ (AKIA PowerPC) を用いた。また、刺激はそのパソコンに接続するモ二タ (SONY Multiscan 17GS) に提示した。刺激の色は灰色で、 輝度は $35 \mathrm{~cd} / \mathrm{m}^{2}$ に作られ、刺激が提示される画面の背景は向 で、輝度は $80 \mathrm{~cd} / \mathrm{m}^{2}$ にした。そして、画面の観察距離を一定 にするため、顔面固定器を画面から $60 \mathrm{~cm}$ の距離に設置し、実 験室内の照度は $460 \mathrm{~lx}$ とした。

\subsection{3. 刺激および手続き}

刺激図形には、歨方形・止菱形・円・止三角形・逆止三角 形止の 5 種類の図形を用いた（図 2-1参照)。基準図形には止
方形を用い、比較図形として上記の 5 種類の図形を用いた。表 2は、刺激図形の面積と視角 (縦横の長さまたは直径)を示す。 刺激図形の数は、実験の目的により視角を 3 段階に変化する ため、基準図形が 3 種類で、比較図形は 15 種類であった。た とえば、面積がそれぞれ $24 \mathrm{~cm}^{2} 、 48 \mathrm{~cm}^{2} 、 96 \mathrm{~cm}^{2}$ の基準図 形の場合、一辺の視角は、4.90deg, 6.93deg. 9.80deg となっ た。刺激図形の配置は、それぞれの試行において、モ二夕画 面の左側に基準図形が提示され、右側に 5 種類の比較図形が ランダムに提示された。比較図形は、小から大に変化する上 昇系列 (small : 12-36 $\mathrm{cm}^{2}$, medium : 24-81 $\mathrm{cm}^{2}$, large : 48$216 \mathrm{~cm}^{2}$ ) と、大から小に変化する下降系列（small : 36-12 $\mathrm{cm}^{2}$, medium : 81-24 $\mathrm{cm}^{2}$, large : 216-48 $\mathrm{cm}^{2}$ ) の2系列か らなるようにプログラムされた。

被験者には、画面左側の基準図形の大きさと比較し、右側 の小から大 (上昇系列) へと大きさが変化する比較図形の大 きさを、基準図形と同じ大きさに見えた瞬間、マウスを操作 し、右側の比較図形の動きを止めるように教示した。同様に、 大から小（下降系列）の動きに対しても同じ方法で比較図形 の見えの大きさを調整するように教示した。結果の分析にお いては上昇系列の調整值と下降系列の調整值の平均を主観的 等価值 PSE [注 14］として用いた。

\section{3. 結果および考察}

図2-2に、視角条件ごとにプロットされた比較図形の知覚 的大きさの実験結果を示した。ここで表す数値は、主観的等 価值により求められたもので、 $\mathrm{PSE}_{\mathrm{c}} / \mathrm{PSE}_{\mathrm{s}}$ は知覚的大きさ、 すなわち図形の過大視あるいは過小視の程度を示す錯視量を 意味するものである。PSE $\mathrm{C}$ は、基準と同じ大きさに知覚され た各比較図形（正方形以外の）の主観的等価値を、PSE $\mathrm{S}_{\mathrm{S}}$ は基 準と同じ形の正方形の主観的等価値を示す。図 2-2でのそれ

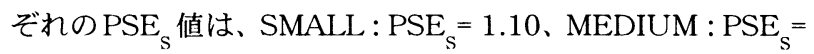
0.92、 LARGE-PSE $\mathrm{s}_{\mathrm{s}}=1.03$ となり、それぞれの $\mathrm{PSE}_{\mathrm{S}}$ 值から 


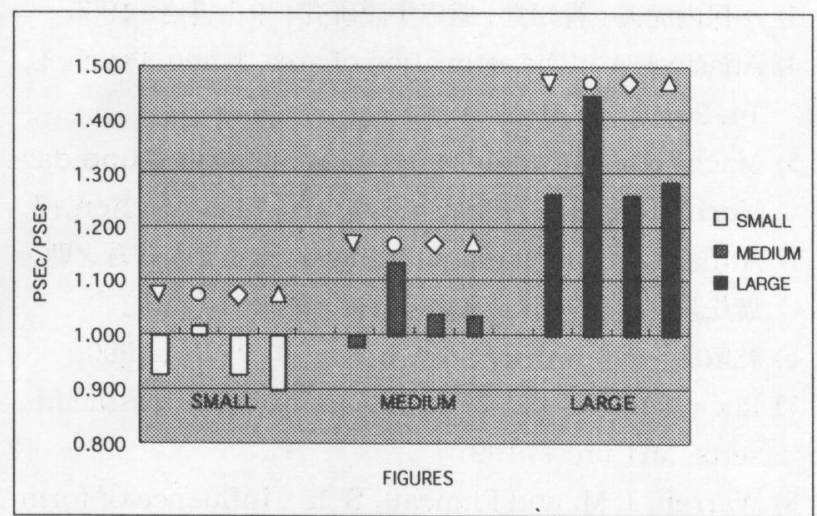

図 2-2 : 視角条件おける大きさ知覚の結果

それぞれのPSE を割った結果が図2-2に示した主観的等価値 である。図2-2の結果から、SMALL・MEDIUM・LARGEの 視角の変化が大きさ知覚に影響していることが確かめられた。 特に、視角が大きくになるに゙つれて、歨三角形・逆三角形・菱 形の知覚的大きさが大きくなる方向に変化することが示され た。また、図2-2のSMALLの結果、逆三角形・止三角形・菱 形の主観的等価値が 1 より低い值を示したことは、小川 [注 15] の研究における「止三角形がもつと大きく知覚され、菱 形が止三角についで大きく知覚されたことと、止方形と円の 大きさがあまり違わない」との報告した結果と近似した結果 である。しかし、視角MEDIUMでの結果は、逆三角形と円形 がSMALLでの結果と同じ傾向であったが、菱形と三角形は 逆の傾向を示した。さらに、視角が最も大きいLARGEでは、 逆三角形、円形、菱形、正三角形のいずれの図形も主観的等 価値が 1 より大きく、基準より過小視される結果を示した。

これらの結果を形と視角の2要因分散分析の検討した結果、 形と視角の主効果 (形 : $F(4,56)=9.644, p<.0001$; 視 角 : $F(2,28)=72.066, p<.0001)$ およびその交互作用（F $(2,112)=9.702, p<.0001)$ が、いずれも有意であった。 そして、主効果の有意差が見られた形と視角に対する Post Hoc 検定 (scheffeの手法により) の結果、視角 SMALLに対 してMEDIUMとLARGEがそれぞれ有意（MEDIUM： $p<$ .005, LARGE : $p<.0001)$ を、MEDIUMに対してLARGE が有意 $(p<.0001)$ であることを示した。形に対するPost Hoc 検定結果では、SMALLの止三角形に対して止方形と円 形がそれぞれ有意（止方形 $: p<.05$, 円形 : $p<.05$ ）を示し、 LARGEの止方形に対して菱形、逆三角形、止三角形、円形が、 それぞれ有意 (菱形 : $\mathrm{p}>.005$, 逆三角形 : $p<.005$, 止三

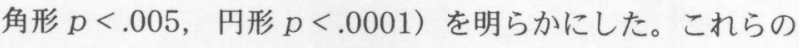
分析結果は、実験 I の実験結果やこれまでの大きさ知覚に関 する先行研究の結果で菱形と止三角形などが止方形より過大 評価されるといつた結果が、視角の変化により変わる可能性 があるということを示唆した。これは、Bingham [注 16] が 究明したように、形の差異、すなわち形態情報が大きさ知覚 に関係していることと、また網膜像の大きさが大きさ知覚に 直接的な関係をもつことから、これらの二つの要因が大きさ 知覚の規定要因であると考えられた。つまり、網膜に映され
た像のすべてが同じ大きさであっても網膜座標が異なると知 覚に変化をもたらし、観察距離が一定で同形の形であっても 網膜像の大きさが変化すれば、形態情報から導かれる大きさ 知覚が変化すると考えられた。そして、このような考察は、 Dumais \& Bradley の研究結果からも理解できる。Dumais \& Bradley は、形の知覚と大きさ知覚の関係を、図形の大き さ・観察距離および照明水準を組合せた条件において、主観 的輪郭の強さを測定したが、この研究結果、主観的輪郭の強 さが照度および視角の対数に比例して減少することが明らか となつた。この研究結果は、主観的輪郭に限られた結果では あるが、視角が主観的輪郭の大きさ知覚に関係していること を示唆し、視角が大きいと輪郭が知覚されにくくなることを 示した。つまり、Dumais \& Bradleyは、視角の効果の理論 的な意味を明確に記述してはいないが、網膜的大きさが現像 を生起に決定的な影響をあたえるという事実が、主観的輪郭 の発生メカニズムを考えるうえで重要であることを明らかに した。

また、形と視角による大きさ知覚に関しては、視覚情報処 理の基礎として用いられる視野との関連で考察することもで きる。多くパターン認識研究では、パターンまたは形という ものの情報処理の過程においての視野について述べることが 多い。視野とは、われわれが目を動かさず視覚の及びうる全 範囲をいうもので、パターンまたは形を認識するには視野制 限が重要とされる。そして、形が認識できる視野の範囲を有 効視野 (effective visual field, [ 注 17]) といい、このよう な視野は視角を単位としている。また、パターンおよび形の 認識における有効視野は、知覚の範囲 (perceptual span) と も理解され、知覚の限界と密接に関連している。このように 形が知覚されるためは、視角の制限も必要とされ、さらに、大 きさ知覚をするためにも、形の知覚とともに知覚の範囲を規 定する視角がいると考えられる。たとえば、通常、正常の視 力をもつ人が本を読むときや、またはあるものを見るとき、す ぐの目の前ではなく、少しい離れた時点で見るのは、形が把 握できる視野をつくる行為であると考えられる。また、映画 スクリーンや看板、大きなポスターなどを見るとき近すぎて その絵の形や文字がうまく見えなかった経験からも、ものの 視角が形の知覚や大きさ知覚に重要であることが理解できる。 そして、Watanabe \& Yoshida [注 18］は、形と視角の関係 を調べた研究で、大きさが視角 $15 \sim 17^{\circ}$ のパターンを中心 視 $\left(3^{\circ}\right.$ 視野 $)$ で見た場合、その形が把握できないと報告して いる。ただし、この研究は中心視に限られた結果ではあるが、 視角が形態知覚に大きく影響を及ぼすことを示唆している。

以上、本研究の結果から、網膜像の大きさを示す視角がパ ターンまたは形の知覚にいかに重要で、また大きさ知覚の規 定要因の一つであることが明らかとなつた。

\section{4. 全体的な考察}

これまでの研究結果より、同じ面積をもつ図形であっても 図形の幾何学的属性が異なれば、知覚的大ささに影響を及ぼ し、また、同形系列の形であってもその視角が異なれば大き 
さ知覚に影響を及ぼすことが明らかになった。ところで、な ぜ形態的な特徵が我々の知覚に影響を及ぼし、形態のどのよ うな要因が面積知覚に錯視現象をもたらせるかなどについて は、次のような研究からさまざまな形態的要因が考えられる。 Binghamの研究では、形の知覚が大きさ知覚を導くと記述 している。しかし、この研究は、見えの形が測定されている わけではなく、先験的に仮定された形態の変数によって直接 的に形の知覚が規定され、間接的に大きさ知覚が導かれると 述べている。そして、Smith [注 19] は、同一面積（形は正 方形のみ）のランダム図形を用いた研究で、図形の幾何学的 な変数が大きさの判断に影響することを示している。そして、 図形を構成した幾何学的な変数のうち、輪郭全体の長さ (perimeter)、屈折数 (number of turns)、図形の横幅 (breadth)、外部の面積 (external area) という4つの変数 が大きさ評価値と負の相関関係をもつと報告している。この 結果を、本論の表 3 の刺激図形の物理的な大きさとの関連で 考察してみると、各図形の縦横の直径を示す $a 、 b$ 值が三角 形と菱形は他の図形より大きい反面、正方形と円形は比的小 さかったことが分かる。また、表 3 に示す $\mathrm{a}$ と $\mathrm{b}$ の長さによ り、輪郭全体の長さと大きさ知覚との関係が負の相関関係を もつというSmithの研究結果との関連で検討してみると、本 研究の結果では、より大きく知覚をされた三角形の方が一番 長く、輪郭全体の長さと大きさ知覚との関係が正の関係を示 していた。これは、Smithの研究が止方形の 1 種類のみの結 果である反面、本研究結果は形態が異なつた 5 種類の刺激図 形によるものであるからだと考えられる。また、面積と形の 関係を心理物理学的測定で行われた Behram \& Brown の研 究では、物理的に等しい面積を持つランダム四辺形に対して 形の類似性の評価が求められた。この研究の結果では、形の 類似性に対する「集約-分散、compactness-dispersion」、 「細長さ、 elongation」、「きざきざさ、jaggedness」という 3 つの心理学次元が報告され、これらの心理学次元に対応する 形態の幾何学的変数を「周の長さ」、「縦横比」「4 つの内角」 であることを明らかにした。

以上、大きさ知覚は、形のさまざまな属性と対応関係があ り、幾何学的な形態変数が大きさ知覚の規定要因でもあるこ とが示唆された。さらに、大きさ錯視効果を、視覚環境の快 適さを求める場面に利用できる可能性も考えられた。つまり、 より大きく・より見えやすく・より見分けやすくする条件を 満たすものつくりや計画に、本研究は有効データの提供がで きる。これからの感性上学研究には、形の属性からなる心理 的、知覚的特性研究による基礎データがもつとも必要であろ うと考えられる。

\section{注}

1) Rudolf Arnheim : Art and Visual Perception, A Psychology of the Creative Eye, The new version, University of California Press, 1974

2) 和田陽平、大山正、今井省吾 : 新編感覚・知覚ハンドブッ ク, 誠信書房, $284,681-715,1981$
3) 小保内虎夫 : 視知覚, 感応学説研究, 中山書店, 1955

4) Anastasi, A. : The estimation of area, J. gen. Psychol., 14, 201-225, 1936

5) Mach, E. : Die analyse der Empfindungen und das Verhaltnis des Physischen zum Psychischen, 7, Auflage, Jena : Gustav Fischer, 1918 [須藤吾之助· 廣松渉（訳）1971 感覚の分析 法政大学出版］

6）乾敏郎 : 視覚情報処理の基礎, サイエンス社, 1990

7) Rock, I. : Indirect perception, Cambridge, Massachusetts, MIT press, 1997

8) Warren, J. M, and Pinneau, S. R. : Influence of form on judgment of apparent area, Percept. Motor Skill, $5,7-10,1955$

9) 前掲書 2) p42-45

10) Behrman,B.W. \& Brown,D,R. : Multidimensional scaling of form : A psychophysical analysis. Perception. \& Psychophysics., 4, 19-25, 1968

11) 田中良久：心理学的測定方法 第 2 版, 1979

12) Teightsoonian, M. : The judgment size. American Journal of Psychology, 78, 392-402, 1965

13) Dumais, S. T. \& Bradley, D. R. : The effect of illumination level and retinal size on the apparent strength of subjective contours. Perception and Psychopysics, 19, 339-345, 1976

14) 前掲書 2) p20, p868

15) 小川降: 異なる条件下の量的判断, 現象的大きさ, 高木 貞二 (編) 心理学における数量化の研究, 東京大学出版会 ,100-117, 1955

16) Bingham, G.P. : Perceving size of tree : Form as information about scale, Jaurnal of Experimental Psychology : Human Perception and Performance, 19, 1139-1161, 1993 a

Bingham, G. P. : Perceving size of tree : Biological form and the horison ratio, Perception. \& Psychophysics., 54, 485-495, $1993 \mathrm{~b}$

17) 前掲書 2) p107, p921, p929, p954,

18) Watanabe, A., \& Yoshida, T. Roles of central and peripheral vision in pattern perception. NHK Technical Monograph,21, 23-31, 1973

19) Smith, J. P. : The effect of figural shape on the perception of area, Perception\&Psychphysics, 5, 49-52, 1969 